\title{
Bilateral internal thoracic artery grafting is superior to other forms of multiple arterial grafting in providing survival benefit after coronary bypass surgery
}

\author{
Ryan Kelly, MD, Karen J. Buth, MSc, and Jean-Francois Légaré, MD
}

Objective: The objective of this study was to examine the effect of arterial grafting on long-term coronary artery bypass grafting mortality.

\begin{abstract}
Methods: Consecutive coronary artery bypass grafting surgeries performed at a single tertiary care center between 1995 and 2007 were reviewed. Long-term survival was compared among patients according to the type of arterial grafts used: no internal thoracic artery, single internal thoracic artery, single internal thoracic artery with other arterial graft, or bilateral internal thoracic artery. Cox proportional hazard models were generated to examine the association of arterial grafting with mortality.
\end{abstract}

Results: A total of 8264 isolated coronary artery bypass grafting operations were performed and followed for a median time of 4.7 years (interquartile range, 2.1-7.5). A single internal thoracic artery was used in the majority of patients $(79 \%)$, multiple arterial grafts were used in $24 \%$ of patients, and bilateral internal thoracic artery grafts were used in $13 \%$ of patients. Patients who received multiple arterial grafts were more likely to be younger, to be male, and to undergo non-urgent surgery. After adjusting for these differences, patients who received bilateral internal thoracic artery grafts were found to have a significant survival advantage when compared with all other patients, including those who received a single internal thoracic artery plus other arterial grafts (hazard ratio, 0.818; confidence interval, $0.672-0.996$ ). Survival at 10 years was $71 \%$ for patients with bilateral internal thoracic artery grafts compared with $66 \%$ for patients with single internal thoracic artery grafts and 58\% for patients with no internal thoracic artery graft. Patients with bilateral internal thoracic artery grafts had significantly better freedom from readmission for acute coronary syndrome (hazard ratio, 0.802; confidence interval, 0.668-0.963).

Conclusions: After adjusting for relevant clinical differences, only multiple arterial grafting using the bilateral internal thoracic artery was able to offer a long-term survival advantage over single internal thoracic artery grafting in patients undergoing coronary artery bypass grafting. (J Thorac Cardiovasc Surg 2012;144:1408-15)

Earn CME credits at

http://cme.ctsnetjournals.org

Since its introduction approximately 4 decades ago, coronary artery bypass grafting (CABG) has established itself as an important therapeutic intervention for patients with symptomatic coronary artery disease. ${ }^{1}$ However, despite the established long-term results of CABG, many have advocated that revascularization with arterial grafts rather than vein grafts offers improved outcomes after $\mathrm{CABG} .^{2-5}$ To date, however, multiple arterial grafting (MAG) has

From the Queen Elizabeth II Health Sciences Center, Halifax, Nova Scotia, Canada. Disclosures: Authors have nothing to disclose with regard to commercial support. Received for publication Sept 8, 2011; revisions received Nov 21, 2011; accepted for publication Jan 6, 2012; available ahead of print Feb 3, 2012.

Address for reprints: Jean-Francois Légaré, MD, Queen Elizabeth II Health Science

Centre, 1796 Summer Street, Rm 2006, Halifax, Nova Scotia, Canada B3H 3A7

(E-mail: jean.legare@cdha.nshealth.ca).

0022-5223/\$36.00

Copyright (c) 2012 by The American Association for Thoracic Surgery doi:10.1016/j.jtcvs.2012.01.030 yet to become the standard approach for the majority of patients undergoing CABG surgery. This is best exemplified by reports from large registries suggesting that the use of MAG is limited to a fraction $(\sim 10 \%)$ of all patients undergoing $\mathrm{CABG}{ }^{6}$

Evidence suggesting a benefit from MAG is based in part on studies that have built on the proven success of left internal thoracic artery (LITA) grafts. ${ }^{2,4}$ As such, LITA + right internal thoracic artery (RITA) grafting, also referred to as "bilateral internal thoracic artery" (BITA) grafting, has been suggested by some investigators to confer a longterm survival advantage when compared with single internal thoracic artery (SITA) grafting. ${ }^{2,3}$ With the use of sophisticated risk adjustment in a group of 10,124 patients from the Cleveland Clinic, Lytle and colleagues ${ }^{3}$ showed that those who received BITA grafting had a significantly decreased risk of death, reoperation, and angioplasty. Likewise, in a meta-analysis of more than 16,000 patients, Rizzoli and colleagues ${ }^{7}$ demonstrated a survival advantage of BITA over SITA use. More recently, a large retrospective study from Guru and colleagues ${ }^{6}$ suggested that there is both a survival and morbidity benefit to MAG compared with 

Abbreviations and Acronyms
ACS = acute coronary syndrome
BITA = bilateral internal thoracic artery
BMI = body mass index
$\mathrm{CABG}=$ coronary artery bypass grafting
$\mathrm{CI}=$ confidence interval
$\mathrm{COPD}=$ chronic obstructive pulmonary disease
$\mathrm{CPB}=$ cardiopulmonary bypass
$\mathrm{EF}=$ ejection fraction
$\mathrm{HR}=$ hazard ratio
ITA $=$ internal thoracic artery
LITA $=$ left internal thoracic artery
MAG $=$ multiple arterial grafting
MHC = Maritime Heart Center
$\mathrm{MI}=$ myocardial infarction
PCI = percutaneous coronary intervention
PHRU $=$ Population Health Research Unit
RITA $=$ right internal thoracic artery
SITA $=$ single internal thoracic artery

single arterial grafts but not specifically BITA use. ${ }^{6}$ However, to date, there are only a few small randomized controlled trials, with some suggesting a benefit to MAG..$^{8-11}$

Work from our group was previously unable to show any advantage of grafting strategies on survival in a series of 4696 patients undergoing CABG. ${ }^{12}$ The present study represents a fresh look at our initial population with the addition of several years of patients and follow-up to 10 years. The goal of this study was to examine a larger population of patients followed for a decade and determine which grafting strategy would independently be associated with longterm survival benefit after CABG.

\section{MATERIALS AND METHODS Patients}

In this single-center retrospective cohort study, all patients who underwent first-time isolated CABG at the Queen Elizabeth II Health Sciences Center from 1995 to 2009 in Halifax, Canada, were identified using the Maritime Heart Center (MHC) Cardiac Surgery Registry. Patients were excluded if they underwent reoperative surgery, if they received fewer than 2 grafts, or if arterial grafting did not include an ITA.

Indications for CABG surgery were based on a weekly peer review process, involving cardiologists, cardiac surgeons, and cardiac radiologists. Individual patients were queued for surgery on the basis of objective criteria as previously described. ${ }^{13,14}$ To facilitate links with administrative longitudinal data, the study population was restricted to patients residing in Nova Scotia at the time of surgery and eligible for provincial health insurance coverage.

\section{Operative Technique}

A median sternotomy was performed in all patients. Off-pump surgery was performed in standardized fashion as previously described. ${ }^{10}$ Briefly, 3 traction sutures were placed in the posterior pericardium for retraction followed by placement of a commercially available tissue stabilizer (Octopus [Medtronic Inc, St Paul, Minn] and Corvasc [CoroNéo Inc, Montreal, Canada]). A nontraumatic small bulldog clamp was then applied to the target vessel proximal to the anastomotic site to achieve hemostasis after arteriotomy. All anastomoses were constructed with continuous suture technique using 7-0 or 8-0 monofilament sutures.

CABG performed with cardiopulmonary bypass (CPB) was performed in a standardized fashion using ascending aortic cannulation and 2-stage venous cannulation of the right atrium. During CPB, mean arterial pressure target was set at $60 \mathrm{~mm} \mathrm{Hg}$ and body temperature was allowed to drift to a minimum of approximately $32^{\circ} \mathrm{C}$. Intermittent cold blood cardioplegia ( $1: 4$ blood to crystalloid with maximal $\mathrm{K}^{+}$concentration $22 \mathrm{meq} / \mathrm{L}$ ) was delivered antegrade via the aortic root unless otherwise indicated.

In all cases, the choice of conduits or construction of grafts was based on surgeon preferences rather than fixed criteria. Arterial conduits were harvested with minimal trauma (non-skeletonized internal thoracic artery) and treated with a papaverine solution or nitroglycerine/calcium channel blocker (verapamil) solution before use. Heparin was given at a dose of 300 to $400 \mathrm{IU} / \mathrm{kg}$ to achieve a target activated clotting time greater than 450 seconds in the CPB group compared with $200 \mathrm{IU} / \mathrm{kg}$ in the beating heart group. On completion of anastomoses, both groups received protamine sulfate to reverse the effects of heparin and return the activated clotting time to preoperative levels. No special blood conservation techniques were used other than non-hemic prime, retransfusion of all contents of the oxygenator at the end of $\mathrm{CPB}$, and acceptance of normovolemic anemia. Postoperatively, non-hemic volume expanders were used routinely.

\section{Postoperative Management}

All patients received intravenous nitroglycerine infusions for the first 24 hours on return from the operating room unless hypotensive (systolic blood pressure $<90 \mathrm{~mm} \mathrm{Hg}$ ). Other routine postoperative medications included daily aspirin and resumption of cholesterol-lowering agents, betablockers, and angiotensin-converting enzyme inhibitors as appropriate.

\section{Outcome Measures}

The primary outcome was all-cause mortality (including perioperative deaths) after CABG surgery. The secondary outcome was readmission to hospital for acute coronary syndrome (ACS) (defined as any myocardial infarction $[\mathrm{MI}]$ or unstable angina) or repeat revascularization, as defined by the International Classification of Diseases, 9th and 10th Revisions, Clinical Modification. Risk-adjusted survival and risk-adjusted freedom from hospital readmission for ACS were examined by Cox proportional hazards modeling and presented as hazard ratios (HRs) with 95\% confidence interval (CI).

For the purpose of our primary analysis, patients were grouped according to grafting strategies: 1) no arterial graft group, 2) SITA graft group, and 3) BITA graft group.

In a secondary analysis, the SITA group was separated into SITA with or without additional arterial grafts in an effort to determine the role of MAG versus BITA in providing a survival benefit post-CABG.

\section{Data Sources}

Data were obtained from established databases and the MHC Cardiac Surgery Registry Database. Longitudinal data were obtained from the Population Health Research Unit (PHRU) at Dalhousie University. The MHC database is a prospectively collected clinical database that collects pre-, intra-, and postoperative information on all patients undergoing cardiac surgery at the MHC. The MHC Registry data were linked to records in the Canadian Institute for Health Information Discharge Abstract Database and the Nova Scotia Vital Statistics database, housed by PHRU. The Canadian Institute for Health Information Discharge Abstract Database enables us to track all readmissions to hospital in Nova Scotia. The Nova Scotia Vital Statistics database collects information on all deaths occurring within the province of Nova Scotia. 


\section{Variable Selection}

Preoperative variables of interest included age, gender, body mass index (BMI), smoking history, diabetes, chronic obstructive pulmonary disease (COPD), hypercholesterolemia, renal failure (serum creatinine $>176$ $\mu \mathrm{mol} / \mathrm{L}$ ), hypertension, peripheral vascular disease, cerebrovascular disease, left ventricular ejection fraction ( $\mathrm{EF}<40 \%$ vs $\mathrm{EF} \geq 40 \%$ ), recent MI defined as the occurrence of an $\mathrm{MI}$ in the 21 days before surgery, intra-aortic balloon pump use, urgency of surgery (emergency for immediate operation, urgent if needed to be performed within 24 hours, in-hospital urgent if the patient was hospitalized before surgery, and elective or outpatient), prior percutaneous coronary intervention (PCI), and number of diseased vessels (triple-vessel or left main disease vs single- or double-vessel disease).

Intraoperative variables of interest included number of distal anastomoses, sequential grafting, complete revascularization (defined as $\geq 1$ grafts to each significantly diseased territory), off-pump surgery, crossclamp time, and total bypass time.

\section{Statistical Analysis}

The clinical characteristics of each grafting group (no ITA, SITA, BITA) were examined univariately. Normally distributed continuous variables were reported as mean \pm standard deviation and compared using analysis of variance. Continuous variables that were not normally distributed were reported as median and interquartile range and compared by the Kruskall-Wallis test. Categoric variables were reported as frequencies and percentages, and analyzed by chi-square or Fisher exact test. Design variables were created for reference level coding of categoric variables with more than 2 levels.

Univariate Cox proportional hazards analysis was performed to examine the prognostic value of each clinical characteristic on the primary and secondary outcomes. Candidate variables for multivariate analysis were selected on the basis of clinical relevance and the significance of univariate associations with a $P$ value less than $.2 .{ }^{15}$ Multicollinearity was assessed using linear regression analysis, where a variance inflation factor greater than 4 indicated intercorrelation among variables. If multicollinearity existed, correlated variables were combined into a single variable or only 1 variable from a set of correlated variables was included in the Cox proportional hazards model.

A non-parsimonious propensity score model was developed to calculate the predicted probability of receiving BITA versus another grafting strategy and included all variables deemed clinically relevant to conduit selection. This approach was used to limit bias that can arise because the effectiveness of a treatment may be dependent on the reasons the treatment was chosen, which in the present case was grafting strategy.

Quintiles of propensity score were used to adjust for potential selection bias in the outcomes models. A non-parsimonious Cox proportional hazards model was used to examine the relationship between grafting strategy and time to death or time to first hospital readmission for ACS, adjusting for all clinically relevant covariates regardless of $P$ value. The assumption of proportional hazards was assessed using the time-dependent covariate test. For each covariate, interaction with time was expressed as "covariate $\times \log ($ time $)$, , and this interaction term was tested in the model. If the time interaction for a covariate was significant, that covariate was modeled as time-dependent by including both the covariate and its time interaction in the model. This approach allowed valid modeling of nonproportional predictors. ${ }^{16}$

In a secondary analysis, SITA cases were separated into SITA with or without additional arterial grafts, and a risk-adjusted Cox proportional hazards model was used to determine the role of MAG versus BITA in providing a survival benefit post-CABG.

Adjusted survival curves were plotted using the corrected group prognosis method of Ghali and colleagues. ${ }^{17}$ All statistical analyses were performed using SAS version 8.2 (SAS Institute Inc, Cary, NC). Although this study included longitudinal data obtained from PHRU, the observations and opinions expressed are those of the authors and do not represent those of PHRU.

\section{Ethics}

This study was conducted with the full approval of the institutional (Capital District Health Authority) Research Ethics Board. The requirement to obtain informed consent was waived under Section 2.1c of the Tri-Council Policy Statement. All personal identifiers were stripped before data analysis to ensure patient anonymity and confidentiality.

\section{RESULTS}

A total of 8264 consecutive patients underwent first-time, isolated CABG between 1995 and 2007. For the primary analysis, patients were grouped on the basis of ITA use: no ITA $(8 \%)$, SITA $(79 \%)$, or BITA $(13 \%)$. Patient characteristics are shown in Table 1. When compared with other groups, patients receiving BITA grafts were younger; more likely to be male; less likely to have renal failure, cerebrovascular disease, low $\mathrm{EF}$, or a recent $\mathrm{MI}$; and less likely to require a preoperative intra-aortic balloon pump. Patients in the BITA group also underwent operation more often on an elective basis when compared with patients receiving SITA or no ITA.

The proportion of patients in whom an SVG was used was significantly different between groups, with only $36 \%$ of BITA, $89 \%$ of SITA, and $100 \%$ of no ITA cases (Table 2). In the SITA groups, the majority of patients received a LITA $(99 \%)$, few received a RITA $(1 \%)$, and some received radial arteries $(13 \%)$. Overall, there were fewer distal anastomoses performed in the no ITA $(2.9 \pm$ 0.8 grafts) and SITA (3.2 \pm 0.9 grafts) groups compared with the BITA group (3.2 \pm 1.0 grafts) (Table 1). Likewise, patients in the BITA group were more likely to be completely revascularized, defined as 1 graft per significantly diseased territory $(88 \%)$, and required a significantly longer clamp time to complete the procedure; in addition, a greater proportion received all arterial grafts $(65 \%)$. One should note that RITA grafts were pedicled in $81 \%$ of patients and used to graft the right coronary territory in $54 \%$, circumflex territory in $25 \%$, and left anterior descending territory in $21 \%$.

The overall unadjusted in-hospital mortality was $2.4 \%$ for all patients undergoing CABG included in the study. Unadjusted in-hospital mortality was lowest in the BITA group $(1.7 \% ; P<.0001)$ (Table 3). Likewise, unadjusted rates of in-hospital permanent stroke were lowest in the BITA group $(0.7 \%, P<.0037$, Table 3$)$. However, the BITA group was more likely to develop a deep sternal wound infection $(1.2 \%, P=.014)$. The rate of deep sternal wound injection in the diabetic patients in the BITA group was $2.54 \%$ (7/276) compared with $0.75 \%(6 / 803)$ in nondiabetic patients (unadjusted outcomes). The unadjusted median length of hospitalization was shortest for the BITA and SITA groups compared with the no ITA group $(P<.0001)$.

To minimize potential selection bias, a propensity score model was developed to predict the probability of receiving BITA and included the following variables: age, sex, BMI, 
TABLE 1. Comparison of preoperative characteristics among patients undergoing coronary bypass grafting

\begin{tabular}{|c|c|c|c|c|}
\hline Variable & No ITA $n=631(\%)$ & SITA n $=6554(\%)$ & BITA $n=1079(\%)$ & $P$ value \\
\hline Age, $y$ & $70.7 \pm 10.2$ & $65.0 \pm 10.1$ & $58.4 \pm 10.0$ & $<.0001$ \\
\hline Female sex & $217(34)$ & $1612(25)$ & $194(18)$ & $<.0001$ \\
\hline \multicolumn{5}{|l|}{ BMI } \\
\hline$<25$ & $177(28)$ & $1325(20)$ & $191(18)$ & \multirow[t]{4}{*}{$<.0001$} \\
\hline $25-29.9$ & $266(42)$ & $2808(43)$ & $486(45)$ & \\
\hline $30-34.9$ & $131(21)$ & $1669(25)$ & $304(28)$ & \\
\hline$\geq 35$ & $57(9)$ & $752(11)$ & $98(9)$ & \\
\hline Smoking history & $434(69)$ & $4610(70)$ & $789(73)$ & .10 \\
\hline Diabetes & $217(34)$ & $2449(37)$ & $276(26)$ & $<.0001$ \\
\hline Hypercholesterolemia & $386(61)$ & $5257(80)$ & $894(83)$ & $<.0001$ \\
\hline Preoperative renal failure & $81(13)$ & $332(5)$ & $19(2)$ & $<.0001$ \\
\hline Hypertension & $431(68)$ & $4388(67)$ & $605(56)$ & $<.0001$ \\
\hline Peripheral vascular disease & $160(25)$ & $1085(17)$ & $154(14)$ & $<.0001$ \\
\hline Cerebrovascular disease & 107 (17) & $879(13)$ & $101(9)$ & $<.0001$ \\
\hline $\mathrm{EF}<40$ & $149(24)$ & $782(12)$ & $78(7)$ & $<.0001$ \\
\hline Recent $\mathrm{MI}<7 \mathrm{~d}$ & $104(16)$ & $467(7)$ & $38(4)$ & $<.0001$ \\
\hline Preoperative IABP & $114(18)$ & $465(7)$ & $34(3)$ & $<.0001$ \\
\hline $\mathrm{CHF}$ & $167(26)$ & $903(14)$ & $69(6)$ & $<.0001$ \\
\hline COPD & $146(23)$ & $919(14)$ & $115(11)$ & $<.0001$ \\
\hline \multicolumn{5}{|l|}{ Urgency of surgery } \\
\hline Elective & $211(33)$ & $3208(49)$ & $661(61)$ & \multirow[t]{3}{*}{$<.0001$} \\
\hline IHU & $185(29)$ & $2357(36)$ & $313(29)$ & \\
\hline Urgent or emergency & $235(37)$ & $989(15)$ & $105(10)$ & \\
\hline Prior PCI & $99(16)$ & $727(11)$ & $131(12)$ & .0022 \\
\hline Left-main/triple-vessel disease & $471(75)$ & $5479(84)$ & $869(81)$ & $<.0001$ \\
\hline
\end{tabular}

$C H F$, Congestive heart failure; $I A B P$, intra-aortic balloon pump; $I H U$, in-hospital urgent (ie, waiting for surgery in-hospital $>24 \mathrm{~h}$ ).

smoking history, diabetes, renal failure, hypertension, peripheral vascular disease, cardiovascular disease, COPD, EF less than 40, congestive heart failure, recent MI less than 7 days, prior PCI, urgency of surgery, left main/triple vessel disease, and surgeon. The propensity score model was well calibrated (Figure 1), and there was adequate overlap of the distribution of propensity scores in the 2 groups. Median propensity score with interquartile range was $0.352(0.203-0.549)$ in the BITA group and 0.0369 (0.0114-0.111) in the non-BITA group. The receiver operating characteristic with $95 \% \mathrm{CI}$ for the propensity score model was $87.0 \%$ (86.2-88.3).

TABLE 2. Intraoperative variables

\begin{tabular}{lcccc}
\hline \multicolumn{1}{c}{ Variable } & $\begin{array}{c}\text { No ITA } \\
(\%)\end{array}$ & $\begin{array}{c}\text { SITA } \\
(\%)\end{array}$ & $\begin{array}{c}\text { BITA } \\
(\%)\end{array}$ & $\boldsymbol{P}$ value \\
\hline No. of grafts & $3(2-3)$ & $3(3-4)$ & $3(2-4)$ & $<.0001$ \\
$\quad$ SVG & 100 & 89 & 36 & \\
LITA & 0 & 99 & 100 & \\
RITA & 0 & 1.1 & 100 & \\
RA & 0 & 13 & 10 & \\
Gastroepiploic & 0 & 0.2 & 0.7 & \\
TAG & 0 & 11 & 65 & \\
LAD disease & 80 & 95 & 94 & $<.0001$ \\
Complete revascularization & 75 & 81 & 88 & $<.0001$ \\
Clamp time & 57 (43-72) & $64(52-81)$ & $72(51-91)$ & $<.0001$ \\
\hline LAD, Left anterior descending; $R A$, radial artery; $S V G$, saphenous vein graft; $T A G$, \\
total arterial grafting (all grafts as arteries).
\end{tabular}

Given the significant differences between groups, Cox proportional hazards analysis was used to adjust for clinical characteristics. Quintiles of propensity score were also included in the models. None of the candidate variables for multivariable modeling exceeded the threshold for multicollinearity. Over the entire follow-up period, 133 patients $(12 \%)$ died in the BITA group compared with 1434 patients $(22 \%)$ in the SITA group and 305 patients $(48 \%)$ in the no ITA group $(P<.0001)$ (Table 3$)$. After adjusting for clinical covariates and propensity score in a model using SITA as

TABLE 3. Unadjusted in-hospital and long-term outcomes after coronary artery bypass grafting

\begin{tabular}{lcccc}
\hline \multicolumn{1}{c}{ Outcome } & No ITA $(\%)$ & SITA $(\%)$ & BITA $(\%)$ & $P$ value \\
\hline In-hospital outcomes & & & & \\
$\quad$ Mortality & 7.3 & 2.1 & 1.7 & $<.0001$ \\
$\quad$ Stroke & 2.8 & 1.7 & 0.7 & .0037 \\
MI & 1.1 & 1.1 & 0.4 & .067 \\
$\quad$ Deep sternal wound & 0 & 0.7 & 1.2 & .014 \\
$\quad$ infection & & & & \\
Long-term outcomes & & & & \\
$\quad$ All-cause mortality & 48.3 & 21.9 & 12.3 & $<.0001$ \\
$\quad$ Readmission for & 23.9 & 18.1 & 15.8 & .0001 \\
$\quad$ ACS & & & & \\
$\quad$ Median follow-up & $3.5(1.0-6.0)$ & $4.6(2.1-7.5)$ & $5.4(3.1-8.6)$ & $<.0001$ \\
$\quad$ IQR), y & & & & \\
IQR, Interquartile range. &
\end{tabular}




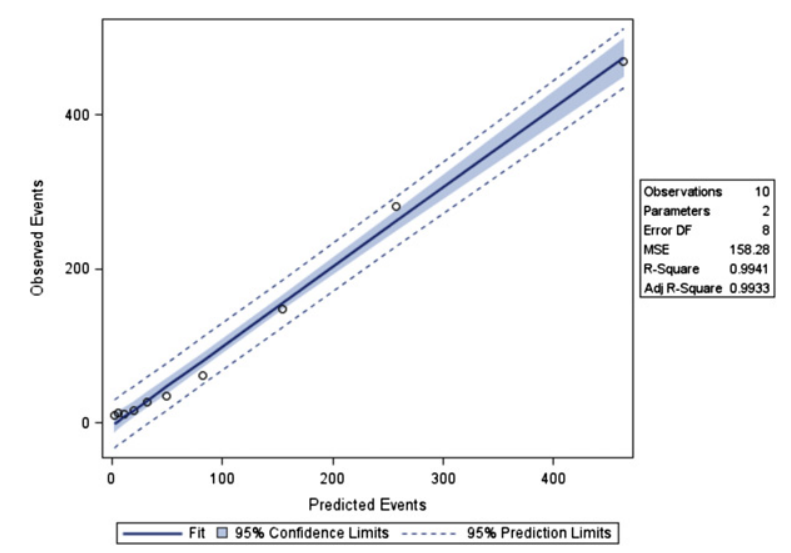

FIGURE 1. Calibration plot of observed versus predicted use of BITA grafting in patients undergoing CABG. A non-parsimonious propensity score model was developed to calculate the predicted probability of receiving BITA versus another grafting strategy and included all variables deemed clinically relevant to conduit selection. Quintiles of propensity score were used to adjust for potential selection bias in the outcomes models. $D F$, Degrees of freedom; MSE, mean squared error.

the reference group, BITA grafting emerged as a significant independent predictor of long-term survival (HR, 0.818; CI, $0.672-0.996)$ and no ITA grafting as an independent predictor of death after CABG (HR, 1.42; CI, 1.24-1.62). In other terms, BITA grafting was shown to be associated with a significant long-term survival benefit with risk-adjusted survival (Figure 2) and showed a $71.0 \%$ survival in patients at 10 years compared with $65.9 \%$ for SITA and $57.6 \%$ for no ITA. After discharge, 192 patients $(17.8 \%)$ in the BITA group were readmitted for cardiac reasons, defined as ACS or repeat revascularization, compared with 1265 patients $(19.3 \%)$ in the SITA group and 155 patients $(24.6 \%)$ in the no ITA group $(P=.002)$. This included 55 patients $(5.1 \%)$ in the BITA group, 334 patients $(5.1 \%)$ in the SITA group, and 30 patients $(4.8 \%)$ in the no ITA group who were readmitted for repeat revascularization in the form of PCI or CABG surgery $(P=.93)$. Repeat CABG

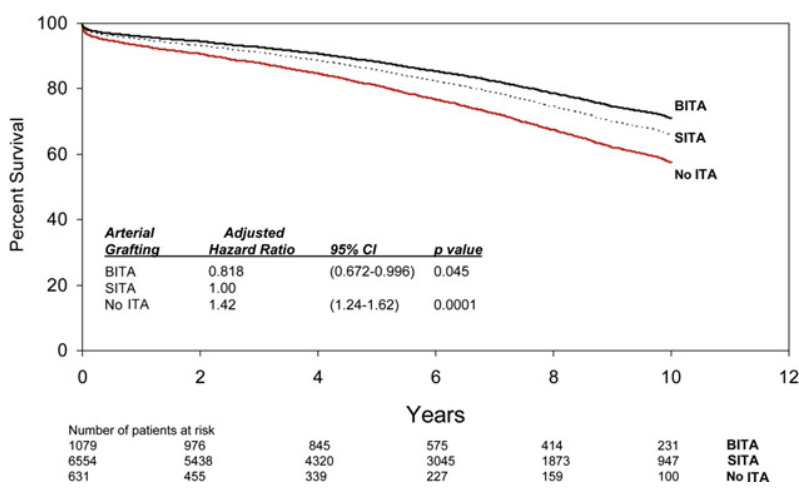

FIGURE 2. Risk-adjusted freedom from death among no ITA, SITA, and BITA groups. BITA, Bilateral interal thoracic artery; $C I$, confidence interval; ITA, internal thoracic artery; SITA, single internal thoracic artery.

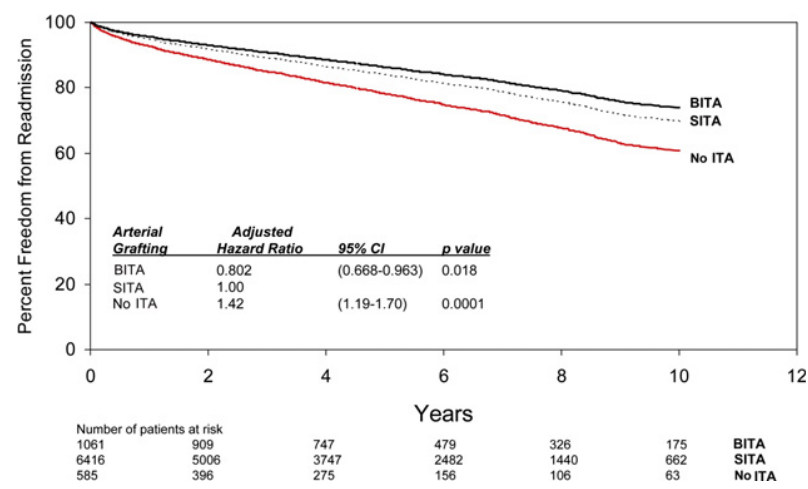

FIGURE 3. Risk-adjusted freedom from admission to hospital for ACS among no ITA, SITA, and BITA groups. BITA, Bilateral interal thoracic artery; $C I$, confidence interval; ITA, internal thoracic artery; SITA, single internal thoracic artery.

was required in $1 \%$ of the patients in each group $(P=.60)$. Given that the rates of repeat revascularization were no different between groups, we looked at freedom from readmission to hospital for ACS, defined as any MI or unstable angina (Figure 3). After adjusting for clinical covariates, BITA grafting was associated with a significantly better freedom from readmission to hospital for ACS when compared with SITA or no ITA $(P=.018)$, suggesting that a mechanism for the improved survival observed in patients with BITA grafting may be protection against later myocardial ischemic events.

The following variables were also found to be independent predictors of mortality: increased age ( $\geq 60$ years), COPD, female gender, diabetes, preoperative renal failure, peripheral vascular disease, low $\mathrm{EF}(<40 \%)$, extremes of weight (low and high BMI), non-elective surgery, failure to receive an ITA graft, and incomplete revascularization (Table 4).

Given that a number of patients in the SITA group also received additional arterial grafts, we performed a separate analysis to determine whether MAG (other than BITA) was associated with a survival benefit. In this additional analysis, patients with MAG were defined as patients with SITA in whom 1 or more additional arterial grafts (not SVG) were used without using BITA. In this Cox proportional hazards analysis, patients were separated into 4 groups: no ITA, SITA (only saphenous vein graft), SITA (+other arterial grafts), and BITA. With this approach, there was no apparent survival benefit to receiving additional arterial grafts to a LITA if this arterial graft was not the RITA (Figure 4). After adjusting for covariates, BITA grafting remained associated with a survival benefit when compared with all other forms of grafting.

\section{DISCUSSION}

In this large prospective registry (8264 patients) including all consecutive patients who underwent $\mathrm{CABG}$, we 
TABLE 4. Non-parsimonious Cox proportional hazards model for survival

\begin{tabular}{lcc}
\hline \multicolumn{1}{c}{ Variable } & Adjusted HR & $\mathbf{9 5 \%}$ CI \\
\hline No ITA & 1.42 & $1.24-1.62$ \\
SITA & 1.00 & \\
BITA & 0.818 & $0.672-0.996$ \\
Incomplete revascularization & 1.23 & $1.10-1.38$ \\
Age $<$ 60 y & 1.00 & \\
Age 60-69 y & 1.75 & $1.49-2.06$ \\
Age 70-79 y & 2.96 & $2.52-3.48$ \\
Age 80+y & 4.86 & $3.96-5.98$ \\
BMI <25 & 1.20 & $1.07-1.34$ \\
BMI 25-29.9 & 1.00 & \\
BMI 30-34.9 & 1.00 & $0.89-1.13$ \\
BMI $>$ 35 & 1.22 & $1.04-1.43$ \\
Diabetes & 1.50 & $1.35-1.66$ \\
RF & 2.05 & $1.78-2.36$ \\
PVD & 1.69 & $1.52-1.88$ \\
COPD & 1.66 & $1.48-1.85$ \\
EF $<40$ & 1.80 & $1.60-2.02$ \\
Elective & 1.00 & \\
IHU & 1.34 & $1.19-1.52$ \\
Urgent & 1.78 & $1.54-2.05$ \\
Emergency & 1.83 & $1.48-2.26$ \\
Propensity score quintiles & & \\
Q1 lowest & 1.00 & $0.822-1.08$ \\
Q2 2nd lowest & 0.943 & $0.729-0.987$ \\
Q3 middle & 0.848 & $0.699-1.04$ \\
Q4 2nd highest & 0.891 & \\
Q5 highest & 0.853 & \\
\hline
\end{tabular}

$\overline{I H U}$, In-hospital urgent (ie, waiting for surgery in-hospital $>24 \mathrm{~h}$ ); $P V D$, peripheral vascular disease; $R F$, renal failure (creatinine $>176 \mathrm{mmol} / \mathrm{L}$ ). The model was also adjusted for female sex, cardiovascular disease, off-pump surgery, sequential grafting, and interactions with $\log ($ time $)$ for the time-dependent covariates age, diabetes, $\mathrm{EF}<40$, and urgency of surgery.

used a well-described statistical approach to adjust for clinical differences between CABG groups. The methods used included Cox modeling, which considers time as a variable, and the propensity score, which is used to account for potential bias that arises in allocating a particular treatment, that is, grafting strategy. After adjusting for differences between groups, we showed that ITA grafting provides an incremental survival benefit. This means that patients not receiving an ITA graft were more likely to die during follow-up (HR, 1.42; CI, 1.24-1.62). Conversely, patients who received BITA grafts were found to have a survival advantage (HR, 0.818; CI, 0.672-0.996) when compared with what is often referred to as the standard of care: SITA to the left anterior descending artery. Our findings are in keeping with published work from other investigators who have suggested a survival advantage to the use of BITA grafts. ${ }^{2,18}$ What is novel about our analysis is that we showed that MAG without BITAs was not associated with a survival advantage, with survival similar to that for SITA grafting. Our findings suggest that the survival benefit of MAG proposed by some investigators may have been driven by

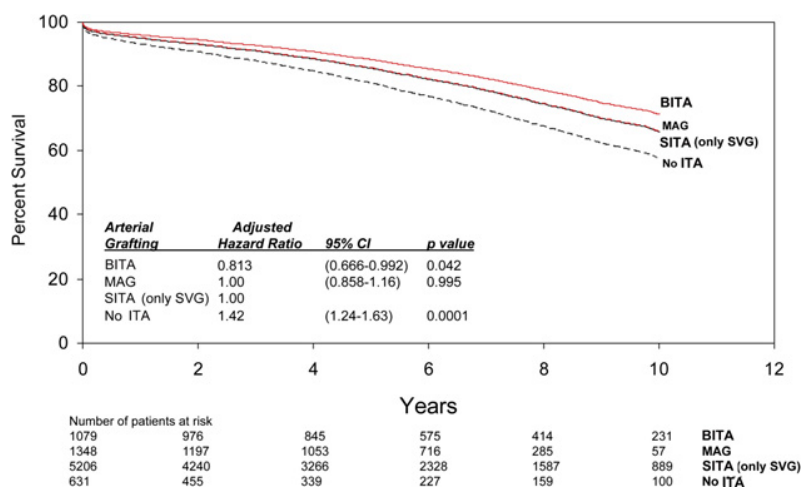

FIGURE 4. Risk-adjusted freedom from death among no ITA, SITA (without additional arterial grafts), SITA (with additional arterial grafts), and BITA groups. BITA, Bilateral interal thoracic artery; $C I$, confidence interval; ITA, internal thoracic artery; $M A G$, multiple arterial grafting; SITA, single internal thoracic artery; $S V G$, saphenous vein graft.

the benefit offered by BITA rather than other non-BITA arterial grafts. ${ }^{6}$ Our findings explain our inability to show a survival benefit in patients receiving MAG in a previous study using half this population and shorter follow-up, and not stratified to BITA grafts. ${ }^{12}$ We provide convincing evidence that BITA grafts are associated with an optimal long-term survival advantage ( $>10$ years) when compared with other forms of grafting. Furthermore, our findings suggest that the separation of the survival curves appears to continue over time, such that this survival advantage will likely persist and become more important in the future.

In a retrospective study such as this, it is difficult to provide a clear mechanism by which BITA grafts are associated with a survival benefit. ${ }^{2,18,19}$ However, we showed that patients receiving BITA grafts had a significantly better freedom from readmission to hospital with an ACS. This observation is important because it provides a mechanism by which BITA may be associated with a survival advantage over conventional saphenous vein grafting by protecting against recurrent ischemic events. Although some have suggested that the benefit of BITA grafting is related to improved freedom from ACS or acute MI, their findings have not been consistent. ${ }^{20,21}$ Although it would be tempting to speculate that the mechanism responsible for less ischemic events in patients receiving BITA grafts would be related to better graft patency, we cannot make that claim. Given that no systematic angiographic follow-up was performed in the present study, we were unable to conclusively link graft patency to improved freedom from ACS or survival.

In the present analysis, it was not possible to explore the exact reason why patients received a particular grafting strategy because this was left to the discretion of the surgeon. This may be particularly evident for the no ITA group, which included 631 patients ( $8 \%$ of all patients). Of note, patients in this group were older (18\% octogenarians), 
$37 \%$ required urgent surgery, and $20 \%$ had no left anterior descending disease. Furthermore, this study spanned approximately 2 decades with evolving notions on the use of ITA grafts for all patients. Additional reasons for not using any ITA graft would include injury to the conduit at the time of harvest, because Queen Elizabeth II Health Sciences Center is a teaching hospital, and poor quality of the conduit, which could not be assessed in the analysis.

Mediastinitis (or deep sternal wound infection) is an infrequent complication reported in $1.2 \%$ of BITA cases in our study, yet a potentially devastating complication after $\mathrm{CABG}$, which is associated with increased cost of care, prolonged hospitalization, and increased morbidity and mortality. $^{22}$ This in part explains some of the reluctance of certain surgeons in using BITA grafts in all patients. Unadjusted univariate rates of deep sternal wound infection were significantly higher in patients with BITA, and given that patients with BITA were generally healthier, this suggests that this observation is likely real. We could not assess the benefit of skeletonized ITA grafts in the present study despite growing evidence of a potential benefit in reducing the risk of mediastinitis. ${ }^{23,24}$ To date, the use of ITA skeletonization has not become standard practice at Queen Elizabeth II Health Sciences Center.

We have provided evidence to suggest that certain grafting strategies, particularly BITA grafts, offer a survival advantage to patients undergoing CABG. However, despite this apparent benefit of a particular grafting strategy, there seems to be huge variability among centers, with the overall proportion of CABG surgeries in which BITA are used. ${ }^{6,25}$ We reported a BITA use of $13 \%$ and MAG use of $24 \%$ in all patients presenting for CABG surgery at Queen Elizabeth II Health Sciences Center over a 17-year period. Although this proportion is not high, it is well above what is normally reported by the published Society of Thoracic Surgeons' database, with a $5 \%$ use of BITAs (available at: http:// wwwstsorg/documents). Given our findings that BITA use would result in better long term-survival, one could speculate that $\mathrm{CABG}$ results may continue to show improvement in the long-term, but only if more surgeons significantly increase their use of BITA grafts.

We did not explore why BITA grafting seems to be underused by many surgeons. One can easily speculate that the lack of obvious benefit of this approach early after CABG in comparison with the perceived risks likely contributes. The theoretic benefit of MAG relies heavily on proposed improved long-term patency, which is not associated with an immediate feedback to treating surgeons. This also explains why it has been difficult to obtain conclusive results demonstrating the superiority of one surgical approach when more than 5 to 10 years are needed to begin to see the clinical benefit. This is particularly true when one is faced with the excellent long-term survival of patients undergoing $\mathrm{CABG}$, as illustrated from results from this registry and many others. ${ }^{18,19}$ Finally, although our findings are in keeping with some published literature, one should keep in mind that statistical modeling could not fully adjust for all potentially relevant variables that make a surgeon select a particular patient for BITA grafting. This is best illustrated by the fact that in the absence of conduit problems such as varicose veins, BITA tends to be offered to younger, healthier, less urgent patients who often are expected to do well. In an effort to adjust for this potential bias, we included surgeon in the propensity score model and subsequently used propensity score in the outcomes models.

\section{CONCLUSIONS}

With the use of statistical modeling and risk adjustment, we showed that MAG using BITAs offered a long-term survival advantage over all other forms of grafting.

\section{References}

1. Serruys PW, Morice MC, Kappetein AP, Colombo A, Holmes DR, Mack MJ, et al. Percutaneous coronary intervention versus coronary-artery bypass grafting for severe coronary artery disease. $N$ Engl J Med. 2009;360:961-72.

2. Taggart DP, D'Amico R, Altman DG. Effect of arterial revascularisation on survival: a systematic review of studies comparing bilateral and single internal mammary arteries. Lancet. 2001;358:870-5.

3. Lytle BW, Blackstone EH, Loop FD, Houghtaling PL, Arnold JH, Akhrass R, et al. Two internal thoracic artery grafts are better than one. J Thorac Cardiovasc Surg. 1999; 117:855-72.

4. Loop FD, Lytle BW, Cosgrove DM, Stewart RW, Goormastic M, Williams GW, et al. Influence of the internal-mammary-artery graft on 10-year survival and other cardiac events. N Engl J Med. 1986;314:1-6.

5. Cameron A, Davis KB, Green G, Schaff HV. Coronary bypass surgery with internal-thoracic-artery grafts-effects on survival over a 15 -year period. $N$ Engl J Med. 1996;334:216-9.

6. Guru V, Fremes SE, Tu JV. How many arterial grafts are enough? A populationbased study of midterm outcomes. J Thorac Cardiovasc Surg. 2006;131: 1021-8.

7. Rizzoli G, Schiavon L, Bellini P. Does the use of bilateral internal mammary artery (IMA) grafts provide incremental benefit relative to the use of a single IMA graft? A meta-analysis approach. Eur J Cardiothorac Surg. 2002;22:781-6.

8. Muneretto C, Bisleri G, Negri A, Manfredi J, Carone E, Morgan JA, et al. Left internal thoracic artery-radial artery composite grafts as the technique of choice for myocardial revascularization in elderly patients: a prospective randomized evaluation. J Thorac Cardiovasc Surg. 2004;127:179-84.

9. Muneretto C, Bisleri G, Negri A, Manfredi J, Metra M, Nodari S, et al. Total arterial myocardial revascularization with composite grafts improves results of coronary surgery in elderly: a prospective randomized comparison with conventional coronary artery bypass surgery. Circulation. 2003;108(Suppl 1): II29-33.

10. Muneretto C, Negri A, Manfredi J, Terrini A, Rodella G, Elqarra S, et al. Safety and usefulness of composite grafts for total arterial myocardial revascularization: a prospective randomized evaluation. J Thorac Cardiovasc Surg. 2003;125: 826-35.

11. Damgaard S, Wetterslev J, Lund JT, Lilleor NB, Perko MJ, Kelbaek H, et al. Oneyear results of total arterial revascularization vs. conventional coronary surgery: CARRPO trial. Eur Heart J. 2009;30:1005-11.

12. Legare JF, Hassan A, Buth KJ, Sullivan JA. The effect of total arterial grafting on medium-term outcomes following coronary artery bypass grafting. $J$ Cardiothorac Surg. 2007;2:44.

13. Legare JF, MacLean A, Buth KJ, Sullivan JA. Assessing the risk of waiting for coronary artery bypass graft surgery among patients with stenosis of the left main coronary artery. CMAJ. 2005; 173:371-5.

14. Ray AA, Buth KJ, Sullivan JA, Johnstone DE, Hirsch GM. Waiting for cardiac surgery: results of a risk-stratified queuing process. Circulation. 2001;104: I92-8. 
15. Sun GW, Shook TL, Kay GL. Inappropriate use of bivariable analysis to screen risk factors for use in multivariable analysis. J Clin Epidemiol. 1996;49:907-16.

16. Bradburn MJ, Clark TG, Love SB, Altman DG. Survival analysis part III: multivariate data analysis - choosing a model and assessing its adequacy and fit. $\mathrm{Br}$ J Cancer. 2003;89:605-11.

17. Ghali WA, Quan H, Brant R, van Melle G, Norris CM, Faris PD, et al. Comparison of 2 methods for calculating adjusted survival curves from proportional hazards models. JAMA. 2001;286:1494-7.

18. Lytle BW, Blackstone EH, Sabik JF, Houghtaling P, Loop FD, Cosgrove DM. The effect of bilateral internal thoracic artery grafting on survival during 20 postoperative years. Ann Thorac Surg. 2004;78:2005-14.

19. Stevens LM, Carrier M, Perrault LP, Hebert Y, Cartier R, Bouchard D, et al. Single versus bilateral internal thoracic artery grafts with concomitant saphenous vein grafts for multivessel coronary artery bypass grafting: effects on mortality and event-free survival. $J$ Thorac Cardiovasc Surg. 2004;127:1408-15.

20. Berreklouw E, Rademakers PP, Koster JM, van Leur L, van der Wielen BJ, Westers P. Better ischemic event-free survival after two internal thoracic artery grafts: 13 years of follow-up. Ann Thorac Surg. 2001;72:1535-41.
21. Dewar LR, Jamieson WR, Janusz MT, Adeli-Sardo M, Germann E, MacNab JS et al. Unilateral versus bilateral internal mammary revascularization. Survival and event-free performance. Circulation. 1995;92:II8-13.

22. Toumpoulis IK, Anagnostopoulos CE, Derose JJ Jr, Swistel DG. The impact of deep sternal wound infection on long-term survival after coronary artery bypass grafting. Chest. 2005;127:464-71.

23. Lev-Ran O, Braunstein R, Nesher N, Ben-Gal Y, Bolotin G, Uretzky G. Bilateral versus single internal thoracic artery grafting in oral-treated diabetic subsets: comparative seven-year outcome analysis. Ann Thorac Surg. 2004;77: 2039-45.

24. Boodhwani M, Lam BK, Nathan HJ, Mesana TG, Ruel M, Zeng W, et al Skeletonized internal thoracic artery harvest reduces pain and dysesthesia and improves sternal perfusion after coronary artery bypass surgery: a randomized, double-blind, within-patient comparison. Circulation. 2006;114 766-73.

25. Baskett RJ, Cafferty FH, Powell SJ, Kinsman R, Keogh BE, Nashef SA. Total arterial revascularization is safe: multicenter ten-year analysis of 71,470 coronary procedures. Ann Thorac Surg. 2006;81:1243-8. 